\title{
Discussion on the Reader Service Innovation Mode of Library Based on the "Internet +" Era
}

\author{
Zhenwei Wang \\ Library, Guangdong University of Science and Technology, Dongguan 523083, China
}

Keywords: Internet+; Library; Reader Service; Innovation Model; Discussion

\begin{abstract}
With the continuous development of science and technology, Internet+ thinking has been widely used. The Internet, cloud computing, and big data provide more personalized and professional services for human life and work. In the current library work, services are also more extensive and the library is where people acquire knowledge. The venue is a way to spread knowledge. The main function of the library is to organize and collect documents, and to provide some raw materials for social development and provide relevant consulting services for readers. The related service analysis is conducted for Internet+ library.

Libraries can cultivate people's intelligence acquisition capabilities, coordinate relevant literatures, and mobilize literatures, thereby assisting in socio-economic and cultural development and realizing optimal allocation of library resources. Library can also carry out related academic and intelligence activities. It can be said that the work covered by library is very wide. Under the thinking of Internet+, it is necessary for the library to find its own path of innovation, do the work of development and change, which will better provide the driving force for social, economic, and cultural progress, and serve the general public better.
\end{abstract}

\section{The Role of Internet + Library Service Model}

\section{Diversified Services}

In the situation of Internet+, library services are more diversified and the degree of resource integration is also higher. It can provide readers with a variety of services, however in the traditional reading library management status, the readers basically borrow books to search for literature or access to certain book resources. However, under the service mode of Internet+ Library, readers can obtain their own library resources through the information terminal online. Internet+ Libraries serve readers with modern thinking and mobile Internet information technology.

For example, the reader can obtain corresponding reading services through a mobile phone app and a mobile terminal when there is a need for reading.

\section{Service Spreading}

Traditional library management requires readers to have certain data collection capabilities, or to know the relevant information of books in order to find the books they need. In the current Internet + library, readers can use the big data of the library or related information to collect, search and use the books in the service model, which not only satisfies readers' needs in reading, but also facilitates readers' borrowing, making the readers' borrowing direction and time more liberalized. In addition, under the Internet+ mode, the library can also use cloud computing technology, which can be used to process books later, thus forming a personalized lending service model. The readers can communicate with each other and know about each other, thus forming a modern, intelligent library.

\section{Service Specialization}

In the service mode of the Internet+ library, the reader becomes the main body and library becomes dominant. In the traditional process of library management, the staff organizes the information manually, and the book manager becomes the main body of information search, but in the current Internet+ library model, readers are free to search for information in the library or search for books at home, reducing the time and space constraints and becoming the main body of data.

\section{High Efficient Service}

The service mode of the Internet+ library is an innovation and breakthrough for traditional 
library management methods and service methods. While using Internet technology, technologies such as big data, cloud computing and the Internet of Things are also being used continuously, and even begin to innovate, optimize and upgrade. This can greatly improve the service quality and service level of library, strive to achieve less manual management and high reading efficiency for the readers.

For example, in the service mode of Internet+ library, readers can use their mobile phone to scan the QR code form or electronic ID card for their own information storage. Information can also be integrated and optimized in the personal system. This will facilitate readers' subsequent identification and use of information. The platform of the Internet+ library can be established to integrate various types of library resources, weakening the difficulty of the past information search for readers and providing more efficient services.

\section{Discussion and Analysis of Reader Service Innovation Mode of Internet + Era Library}

\section{Innovation and Reform of Library Service Concepts under the Internet + Era}

Library management must stand out in the flood of informatization society. Therefore, the innovation of service concept is the inevitable result of library service innovation. To improve library service innovation consciousness, the following aspects should be done. First of all, library managers must update their ideas and sense of innovation. The library itself serves a wide range of readers. Institutions can provide readers with a variety of information resources and library resources. Therefore, in terms of their nature, they are positioned to serve the broad masses of readers and services are the purpose. Secondly, professional knowledge training for the librarians and awareness of the modern Internet needs to be done. Some librarians have developed a habit of sticking to conventions in traditional services. Therefore, there will be a sense of absence in their own responsibilities and work directions, so that they must do a good job of pre-job training.

For example, a forum or PPT presentation can be used to display the modern information library service model, so that the library managers can clearly understand the work of the library in the new era and serve readers more actively and proactively.

\section{The Innovation of Library Service Content in the Era of Internet+}

The innovation of service content and service modes of libraries in the Internet+ mode is the mainstream. Specifically, the following aspects can be started. Firstly, in the era of Internet, information is more diversified and presented in a digital manner. The dissemination speed of information resources is very fast, and the spreading in people is also more extensive. Therefore, to make readers enjoy modern book resources better, the library managers need to strengthen their organization and recognition of library digital resources, as well as the classification capabilities. Secondly, the Internet+ empowers people in the library to enhance the readers' characteristic and personalized services.

For example, a university library develops a differentiated book resource service module for different needs of students of different majors. Students can search for information resources for their own major modules. This further improved the quality of Internet library services. Finally, network communication platforms, post bars and websites can be built for the readers, where they can spread and share their own information resources or reading resources.

\section{Personalized Library Service and Massive Data Processing Innovation in the Era of Internet+}

In the era of Internet+, the services of library have already generated a certain distance from traditional library services. Internet+ integrates mobile services and multiple library services. City libraries have social and cultural functions, science and technology development functions, and social life.

For example, robot service projects have begun to be used in libraries in some schools, and radio frequency technology and modern information technology have been integrated. In addition, some libraries begin to integrate the Internet and science and technology into one, and establish an activity to create a personalized database for readers. In accordance with the different reading habits of different readers, a personalized reader membership system is established among each reader. All 
can communicate and share with each other. This action greatly enhances the exchanges among readers, narrows their distance, and makes readers have stronger experience of books.

In the era of Internet+, library resources also present a variety of pictures, not only including books, but also including photos, videos, or courseware and related reading records, and many multimedia resources are integrated into one. Under the Internet+ service model, the data resources of library are not only very large in storage, but also more complex, which can meet the needs of various readers. The library can fully utilize the advantages of the Internet platform. Then, various data are extracted to do a good job of locating and associating with each other to achieve effective management and quick access to library resources.

\section{Thinking on the Reader Service Innovation Model of the Library in "Internet+" Era}

\section{Protection of Readers' Information Security}

In the era of big data and the era of Internet+, information has brought great convenience to library management and readers, but at the same time there are also hidden problems in information security. Readers' reading behavior and personal data are collected into data with large quantity, and the value density and accuracy is high. These data can make the service of library more accurate and scientific, but the personal information protection is also an important item in the library services. In order to improve the goal of personalized service, the readers' privacy data also needs to be protected and taken precautions. For example, add multi-layer password recognition and firewalls to prevent bad molecules from entering the network database to gain readers' information.

\section{Enhancing the Reliability of Internet of Things Technology}

In the Internet+ library service model, some documents can be retrieved and obtained. However, the completion of these tasks will depend on Internet of Things technology. The Internet of Things technology has certain reliability. For example, some of the more high-end libraries in the city have already used them. For self-service type, rf id chips are installed inside the document by means of a machine, but there are certain problems found through actual borrowing. The stability of the machine is relatively low, and the chip is also prone to damage. Therefore, it is also necessary to continuously improve the Internet of Things technology. With the support of the Internet of Things technology, all service work can be more stable, safe and reliable.

\section{Conclusion}

In summary, the readers service innovation model of library in the "Internet + " era is analyzed in this paper. In the "Internet + " era, readers services of library should be innovated, so should the methods. Only in this way can the development of libraries be met.

\section{References}

[1]Yazdi, F.A.,Deshpande, N.J..Evaluation of selected library associations' web sites[J].Aslib Proceedings, 2013,65(2):92-108.

[2]Milman, B.L.,Zhurkovich, I.K..Towards a full reference library of MSn spectra. II: A perspective from the library of pesticide spectra extracted from the literature/ Internet[J].Rapid Communications in Mass Spectrometry: RCM,2011,25(24):3697-3705.

[3]D'Elia G,Abbas J,Bishop $K$ et al.The impact of youth's use of the internet on their use of the public library[J].Journal of the American Society for Information Science and Technology,2007,58(14):2180-2196.

[4]George D'Elia,Corinne Jorgensen,Joseph Woelfel et al.The Impact of the Internet on Public Library Use: An Analysis of the Current Consumer Market for Library and Internet Services[J].Journal of the American Society for Information Science and Technology,2002,53(10):802-820. 